\title{
André-Marie Despringre
}

\section{Meaning of the old and new cultural variations of a French song from Brittany}

\section{Introduction}

The meaning of a given song which is by definition polysemic, demands a research method that uses a series of analyses: one needs to analyse the subject matter and forms of the poetic and rhythmic-melodic expressions, forms and subject matter of their content, and of their different uses. This is generally a collective work (for example the work of my Musilingue group: Crochu et al 1991, Despringre 1997). It cannot however be totally developed in this article for material reasons. The pertinence of the relationships established between the above mentioned levels of analysis comes from a dialogue between my ethnographic inquiry and the musicians, between my transcriptions by ear and the different models that I propose. The object of this study is featured as a symbolic system which is ruled by the constraints of both its production and its perception. To approach this ideal and to properly delimit the constant elements within the variables, I have set to work the semiotic principle of replicability (see Peirce 1931-35; Eco 1992) which comprises both homology and the repetition of various elements. The application that I am attempting with Miller's Song allows me to set forth some of the more significant functions, the ones that Hjelmslev (1963) calls 'fonctifs'. These 'fonctifs' represent all the relationships that can be established between each level of the 'expression' and each level of the 'contents' of the song, between the sung form itself and its immediate social context. The 'fonctifs' allow me to establish in a rigorous manner the modalities of the meaning of the song when observed in a certain setting. They help us to understand how, for example, the old French cultural context of the song, shows, even if only from the study of one given song, a certain number of important formal changes which contrast with the more stable literary content or with the more erratic poetic-musical content. After a quick demonstration of this situation and of its incidences on the future of the song, I will examine the song in a completely different context, which highlights other types of changes brought about by its instrumentation chosen by the Breton revivalists.

The problem was first to find a corpus that would illustrate, in the current recorded documentation (which in France is rather scarce), some significant 'fonctifs' of the transformations of a song (here the Miller's Song) as it passes from one culture (of the Jura) to another (of Brittany), and also to show how the revivalists of High-Brittany modify the same song by their instrumentation. 
Semiologists Jean Molino (1975) and Jean-Jacques Nattiez $(1976,1987)$ called this: 'poetic' and 'esthesic' respectively. In this perspective, the transcribed musical work shows both its subject matter and its forms but also the 'trace' of the producer or singer. Note that if Nattiez (1976) often cites Hjelmslev, who is considered in France as the father of post-Saussurian semiology, he nevertheless only considers this researcher to be a pure linguist and as such does not really take into consideration the study attempted in this article.

This topic implies the practice of the formal analysis of French monodies according to semiotic methods. ${ }^{1}$ By comparing the forms from High-Brittany to High-Jura that show the progressive musical evolution of Breton militant practices that developed from 1970 to today, I will show which of the musical choices became selected more often by 'revival' musicians. I attempt to describe the poetic and musical system of songs, the 'fonctifs' (relationships between the elements of the expression and the elements of the content), the principal morphological rules of their functioning, and also point out the significant differences between sung and instrumental interpretations.

The selection of a typical repertory is normally based on the more and more conscious reconstruction of a tradition. The question asked is 'what are musicians conscious of?' Their intuitions are never founded on scientific studies but stay voluntarily spontaneous. In consequence, the exposes on traditional music deal with the reconstructed tradition by the folklorists, that is 'starting from' the old. The selection uses criteria like the dialect or local speech, the literary themes of a historical type, geographic reconstructions of the local/regional sites, local characters, mythical beings and stories etc. Dance music is favoured, diminishing the status of pure songs. An evolution has been felt for the last twenty-five years: one can witness the integration of musical instruments from the traditional culture and of 'folk' instruments that are totally foreign to the region.

The analytical method outlines the incidence of the instrument rather than the variation and musical mutations. The latter can be formal or stylistic. There exists a respect for Breton musical foundations that manifests itself in varying intensity according to the levels of the realization of an 'authentic' style. This explains the important variety of the interpretations of the same monody that we notice in Brittany.

The criteria of replicability of the different elements (see Eco 1973; Ruwet 1975; Nattiez 1976; Arom 1985; Crochu et al 1997) are the most pertinent to represent the poetic and musical systems. The diversity and variance of structures and systems are linked with the noted musical foundations. Expressive systems and contents tied to the use of forms, are thus described for the song and for its instrumental version. Significant differences appear on the level of the formal organization, on the use of possibilities specific to each instrument taken into consideration (bagpipes/bombarde, accordion, violin and clarinet).

The revival as it was developed in France from 1970 to these days, confronts

${ }^{1}$ Semiotic models of Charles Sanders Peirce (1931-1935), Louis Hjemslev (1943), Umberto Eco (1973, 1976), Jean Molino (1975) 
us with evidences which are shared by other similar movements found throughout Europe and the world. These evidences, erected in character by us researchers, issue from the varied practices of musical re-establishment. Their specificity resides of course in the particular modalities of some musical practices (the most spontaneous ones possible), an apprenticeship based on imitation (from master to disciple) and a transmission, preferably an oral one. These sociological and cultural movements are often placed, not without logic, in the ecological 'move'. They contribute without a doubt, to the development of a new musical spirit. Similar in essence, they are indifferently qualified as 'music of France', 'ethnic music', 'traditional music', 'popular music', but also 'regional music', 'Flemish music', 'music of Brittany', 'Corsican music' etc. These qualifications present serious difficulties for the analyst. They represent pertinent indices of a very intense symbolic activity, which is not conscious of the reality that is a regional music in its essence.

The works are often produced in new geographic or economic (showbiz) sites, with new techniques (electronic amplification of voices and instruments) etc., but the ultimate founding reference is still the song, it is the identifying monument of this expression. References to the past, local and regional, stimulate a dynamic research into original and unpublished archives of the musical life of a people. This is a legitimate reaction to a cultural globalization that is penetrating and destructive (by the types of expressions and contents that it transmits), almost totally responsible for the near total extinction of the practices that are rooted in the musicians' birthplace. The reactivation of this music is then justified by the memorial virtues that it carries and the convivial atmosphere that it creates. Musical content is taken up spontaneously but in a different way without scientific foundation and without a thought towards this disaffection. This is the principal object of my approach.

In my opinion, the 'known' context of today's 'living' music, might facilitate the theoretical elaboration of the problems already studied by musicologists and musical semiologists. I will only consider here the problem of the limits to be given to the transmitted piece, the song of an oral tradition, through its new instrumental performances. My application is inductive and targets the understanding of some of the causes that determine the qualitative change of a monody, from my observations of the song and of its instrumental interpretation. What I know of the immediate context that presided at its elaboration will be taken into consideration in so far as the real articulation of the music.

Three points will be raised now:

a) Some generalities on the connections between the expressive system of music and its production context, that brings forth its content (Alvarez-Pereyre \& Arom 1992; Hjelmslev 1943; Molino 1975; Nattiez 1976; 1987; Peirce 1931/1935).

b) Three levels of replicating a song (study of a case in Brittany as an illustration)

c) Are the stylistic and formal modifications a result of this setting? 


\section{Generalities on the relationship between music and its production context}

To study the relationships (coded or not) of the music produced - when it is considered as a structured and shaped system within a context (elements of the culture and of the society) - is a very ambitious theoretical undertaking. One needs to approach this question first by explaining how one can position the intrinsic content of a piece against it extrinsic setting. If one considers the intrinsic to be as Arom (1992, 248-251) advocates:

1. The modalities of the combination of the parameters chosen by a society for its music.

2. The modalities of the instrumental or vocal techniques used to bring it forth. 3. The musical system in which musical scales, rhythms and the ordering principles that are often predetermined. Forms and structures are elements of this system.

One can see then that if the 'modalities of usage and combination' or the 'choice of the ordering of the music' effectively contribute to the existence of several systemic and internal aspects of a music, they are also elements that stem from usage, from a cultural order. This means that Arom only considers usage as a function within the music (rites, indigenous terminology etc.). He places everything else in the external, i.e. in the vague 'socio-cultural' domain. However, ideology and individual choices (for example) can also define some musical forms even some forms of expression. In this Arom distances himself from the semiotic tri-partition of Nattiez (1976, 1987) and Molino (1975). Their opposite concept verifies the role of the extrinsic in the 'trace' of the piece, that is in fact in the 'partition' that the searcher establishes. ${ }^{2}$

To recognize the role of the external on the elaboration of the expression and content of a music demands most often an inductive approach but it can in some case require a deductive one. The study of the relationships between the forms of a musical expression and the forms of musical and literary contents, that are both the meaning of the music and its context, is in reality a search for 'semiotic functions' called 'fonctifs'. These fonctifs alone are able to establish rigorously the real meaning of the studied piece. This concept to which I subscribe was first theorized in linguistics by Hjemslev (1943). Depending on the point of view adopted to explain a musical piece (for example, starting with the performance and going back to the piece or the reverse; or yet starting with the perception of the piece to go back to the piece itself or the reverse steps), one will produce different analyses (Nattiez 1987, 156). The pertinence of the analysis will be conditioned in musicology but especially in ethnomusicology where one has all necessary

\footnotetext{
${ }^{2}$ Nattiez commenting on Imberty $(1975,95$ and 1981) and Francés $(1958,299)$ distinguishes three great fields for the extrinsic contexts of music: the spatial-temporal (time experience), the kinetic (psychologic modalities of the movement of sounds are the basis of musical language) and the affective (relative to rhythm).
} 
information - by the contextual dimension (of the performance and of the perception of the musical piece) that the researcher has been able to obtain. The semiology aims to demonstrate how the poetic interpretations (those of the performance) and the esthesic interpretations (those of the perception) are tied to the core of the musical piece.

\section{Three levels of replicating a song}

In the contemporary setting that we have known for the past half century, a setting where instrumental music has come to support and overshadow the song, the problem of instrumentation becomes essential for the person who wants to describe this music and interpret its evolution.

An evolution has taken place for the last twenty years, as folk musicians became conscious of the living nature of this oral tradition. I studied some occurrences of cultural change in Brittany (Western France) (Despringre 1997b). I demonstrated the subjective appreciation of the musicians who first use song books as musical models and later, use their own sound recordings to build local archives (Collection of the Dastum association of Rennes in Brittany). These airs are often sung, accompanied by musical instruments that were not often used anymore by the old folks. In addition, traditional folk instruments have reappeared in the 1990s. Having noticed the local musical repertory and its peculiarities, people use any instrument that is likely to preserve and enhance the monody's value in a more modern way. Electric amplification, notably during concerts and balls, have taken a considerable importance since the eighties.

Musicians choose a selection of typical repertory, basing their criterion on a more conscious reconstruction of a tradition. The problem is: what are musicians conscious of? (see Despringre 1997a). Their intuitions are not often based on scientific research but remain voluntarily spontaneous. Consequently, performances touted as traditional music are more often of a tradition that is rebuilt by the folklorists, based on the 'old'. The selection uses criteria like dialect, local language, literary themes of a historic nature, geographic performances at a local/regional site, local figures, mythical beings and stories etc. Any music showcasing these themes is considered local or regional. Because it adapts itself to the public's taste, dance music is favoured, and diminishes the importance of the place taken by song music. This does not however exclude voluntary attempts at reviving a taste for song music. I will demonstrate some of these points in the dance example of the 'Miller's Song', performed by a group of men from High-Brittany.

We are talking now about a replication of a song, of which several levels can be described:

1) The 'Breton' song is compared with another interpretation of it in Jura (850 $\mathrm{km}$ towards the south-east). I recorded it outside of the context.

2) The song itself passes through an individual performance during a dance to a collective one.

3) The song is studied from the vocal to the instrumental interpretation. Outside 
of the context, in a median framework, the words are taken out, to enhance the instrumental performance of the music.

During the analysis of a 'dominant iconic model' (Eco 1996, 54) we shall see the repercussions of these three levels of duplication, on the several parameters that were used in the choices made.

\section{Descriptions of the Miller's Song}

\section{Level I: Performance sung without dancing}

Here (see Ex. 1 and Ex. 2) we can observe that a similar text is sung with two different airs (content of music) - without dancing - when I have recorded it. Nevertheless, these are two different dances. The first from the Eastern France (branle of High-Jura), the second from the Western (type of gavotte from Brittany). ${ }^{3}$

\section{Poetic: form of content $=$ metaphor}

The text - in its short versions of High-Brittany (see Ex. 3, with one verse and refrain) and High-Jura (Ex. 1, with three verses and refrain), or in the longer version from High-Brittany (Ex. 2, with eleven verses and a refrain) - expresses the same idea. It has an erotic theme to be found in the miller metaphor. It evokes a common occupation (supposedly) of the millers as their millstone grind the grain and when all goes well with the mill's operation. He 'grinds' the young girl (and certainly not the old one as in other versions), fills her sack (after making love to her), the girl becomes pregnant which upsets her father or her mother (depending on the versions).

\footnotetext{
${ }^{3}$ The English translations of the poetic-texts are in Appendix.
} 
Song $n^{\circ} 1$

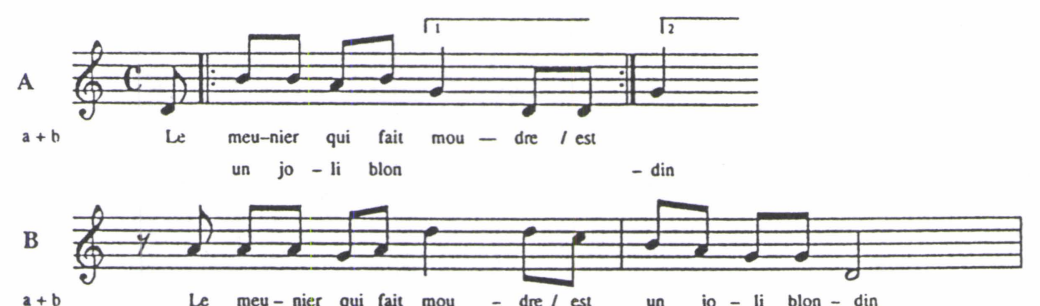

$a+b$ Le meu - nier qui fait mou - dre $l$ est un jo - li blon - din
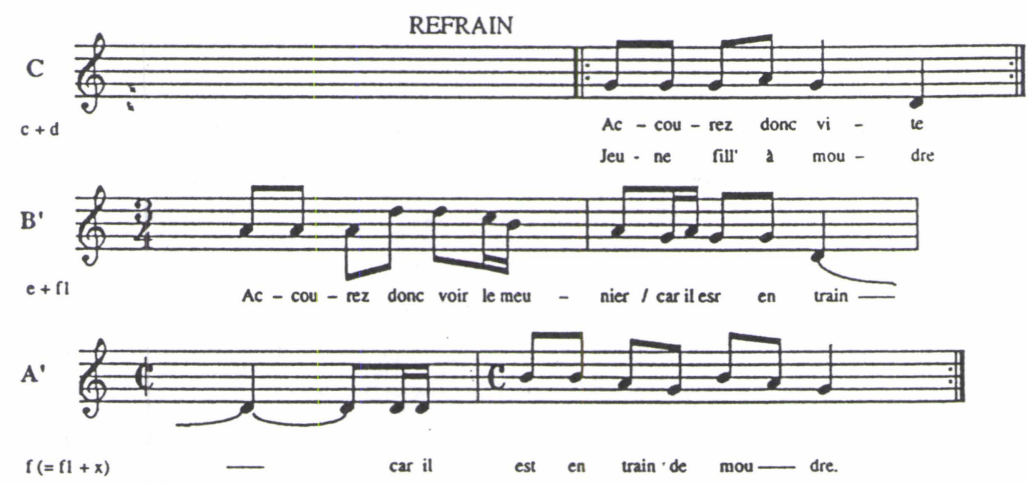

Song $n^{\circ} 2$

High-Brittany, cd, 1996

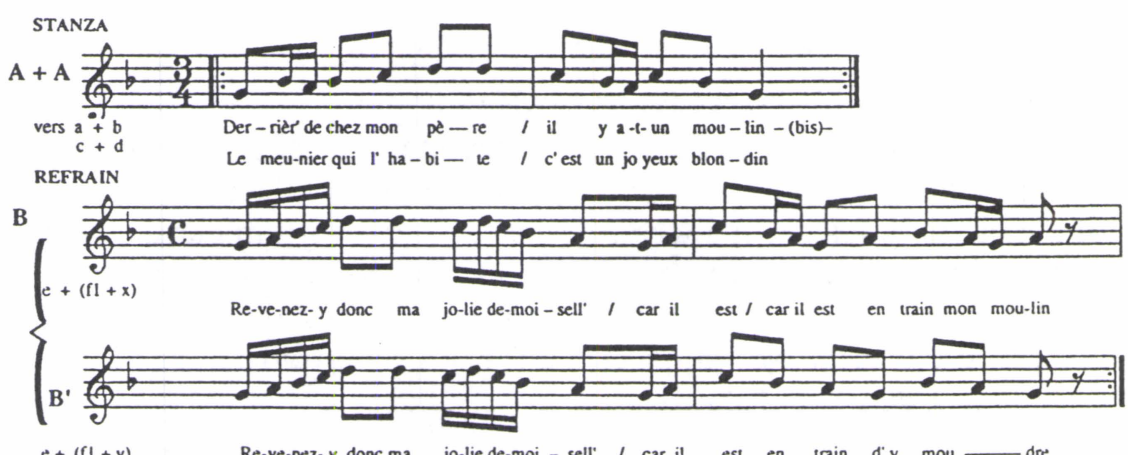

$\mathrm{e}+(\mathrm{fl}+\mathrm{y}) \quad$ Re-ve-nez-y donc ma jo-lie de-moi - sell' / car il est en train d'y mou

note : $\mathrm{fl}=$ car il est en train

$\mathrm{x}=$ mon moulin

$y=d^{\prime} y$ moudre scale/minor
on 2th teracord

12345

Example 1. Music and texts for French songs no. 1 and no. 2

The similarities between the different versions are to be found not in the exact 
identity of the verses but in the similarities of small syntagmas or phrases. This is not an absolute rule.

\section{High-Jura}

The miller who grinds

Is a pretty blond

Because he is grinding the flour

(4th line of the refrain )
High-Brittany

The miller who lives there

Is a happy blond

Because he is grinding the flour there

Example 2. The English translation of the text for Miller's Song.

These syntagmas are really equivalent and show semantic 'slides': to go from pretty to happy in French is a change of the meaning of the adjective but uses a repetition of the consonant 'j' from 'joli' (pretty) to 'j' from 'joyeux' (happy) (see Ex. 1). ${ }^{4}$

These two areas belong to two ancient cultures: the Franco-Provencal culture in the Jura and the Celtic-Gaul culture in Brittany. The French text receives two different rhythmic 'imprintings', belonging to two different sets of mind. This explains why the expressive forms (rhythmic units) and especially the melodic/rhythmic forms, (a way to organize poetic and melodic structures), seem so different and the melodic lines are a bit closed. The song of the High-Jura could not be mistaken for the song of Brittany and vice-versa. The formal organization is typical of a region but the poetic-musical content seem less specialized excepted the rhythm.

Music: form of content (see Table 1 about the similarities of the durations underlying the same verses of the songs in Ex. 1)

We notice that the series 55432 (1) is found under each similar verse (the miller who grinds) or is slightly staggered in time because of the use of a different rhythm. The melodic lines seem different because of the rhythm but the sounds used are very similar (cf. Table 1 for example: B of song no 1 and A for song no 2, etc.). The metres are also alternatively ternary or binary. The rhythm and the melody are preserved correctly by reason of the dance's rigid framework. (See the rhythmic schema of a dance in Table 3.)

\footnotetext{
${ }^{4}$ Without further details here, we can compare many verses by looking at the table showing the compared verses (Appendix: English version of the songs). So, they have with slight variations, a similar poetic text and similar meaning.
} 
ㄱ. ญ

을 해

음

초

근

음

ติ ๓

등. 음

(1) \&

츤 Z

㤖

ญิ 음

장

ㄷํㅇ

힐

ర్ల

믈

도른

웡웡

을 혼



․ㅡ

ఖ

¿을

응 원

ฮิ ఐ

든

크음

른

ज

- 음

잉

은 흐음
Notes are arbitrarily replaced by numbers $1=\mathrm{G}, 2=\mathrm{A}$ etc

Capital letter $=$ musical segment

Lower case letter $=$ poetic segment $($ verse $)$

\section{Versions}

$\mathrm{n}^{\circ} \mathbf{1 / B}$

$\mathrm{a}+\mathrm{b}$

$n^{\circ} 2 / \mathrm{A}$

texte $\mathrm{c}+\mathrm{d}$

$n^{\circ} \mathbf{1} / \mathbf{B}^{\prime}$

$\mathrm{e}+\mathrm{f} 1$

$n^{\circ} \mathbf{1} / \mathbf{A}^{\prime}$

$\mathrm{f}=\mathrm{n} 1+\mathrm{x}$

$\mathrm{n}^{\circ} 2 / \mathrm{B} 1 \mathrm{~B} 2$

$\mathrm{e}+\mathrm{f} 1+\mathrm{x}$

$\mathrm{n}^{\circ}$ 2/B1B3

$\mathrm{e}+\mathrm{f} 1+\mathrm{y}$

$\begin{array}{ccccccccccccc}2 & 2 & 2 & 1 & 2 & 5 & 5 & 4 & 3 & 2 & 1 & 1 \\ \text { Le } & \text { meu } & \text { nier } & \text { qui } & \text { fait } & \text { mou } & \text { dre } & \text { /est } & \text { un jo } & \text { li } & \text { blon din }\end{array}$

\begin{tabular}{lllllllll|l|l|l|}
1 & 3 & 2 & 3 & 4 & 5 & 5 & 4 & 3 & 2 & 4 & 3
\end{tabular}

Le meu nier qui l'ha bi te /c'est un joy eux blon din

\begin{tabular}{llllllllll|lll|l|}
2 & 2 & 2 & 5 & 5 & 4 & 3 & 2 & 1 & 2 & 1 & 1 \\
\hline
\end{tabular}

\begin{tabular}{cccccccccccc|} 
Ac & cou & rez & donc & voir & le & meu & nier & /car & il & est & en \\
5 & - & - & 5 & 5 & 3 & 3 & 2 & 1 & 3 & 2 & 1
\end{tabular}

car il est en train de mou ou dre

$\begin{array}{cccccccccccc}1 & 2 & 3 & 4 & 5 & 5 & 4 & \mathrm{n} & 4 & 3 & 2 & 1 \\ \operatorname{Re} & \text { ve } & \text { nez } & \text { y } & \text { donc } & \text { ma } & \text { jo } & \text { lie } & \text { de } & \text { moi } & \text { sell' } & \text { / car }\end{array}$

\begin{tabular}{lllll|l|l|l|l|l|l|l|l|l}
1 & 2 & 3 & 4 & 5 & 5 & 4 & 5 & 4 & 3 & 2 & 1
\end{tabular}

\begin{tabular}{|l|l|l|l|l|l|l|l|l|l|l|l|l|l|l|l|l|l|l|l|l|l|l|}
\hline 4 & 3 & 2 & 1 & 2 & 1 \\
\hline
\end{tabular}

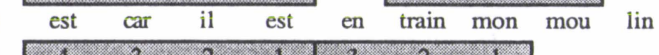

\begin{tabular}{|cccc|ccc|}
\hline 4 & 3 & 2 & 1 & 3 & 2 & 1 \\
\hline
\end{tabular}




\section{Level II: Performance sung while dancing}

Poetics: form of content

Third expression of the song (Ex. 3; see also Despringre, 1997d) ${ }^{5}$ is constituted with metaphors (erotic connotations) which give strength to a dance or a song (Photo 1 pictures the dance). The refrain 'in response' adds an important element to the integration by all of the meaning of the words. Even though it is particular to Brittany, the same song with the same images exists in the Jura and other places.

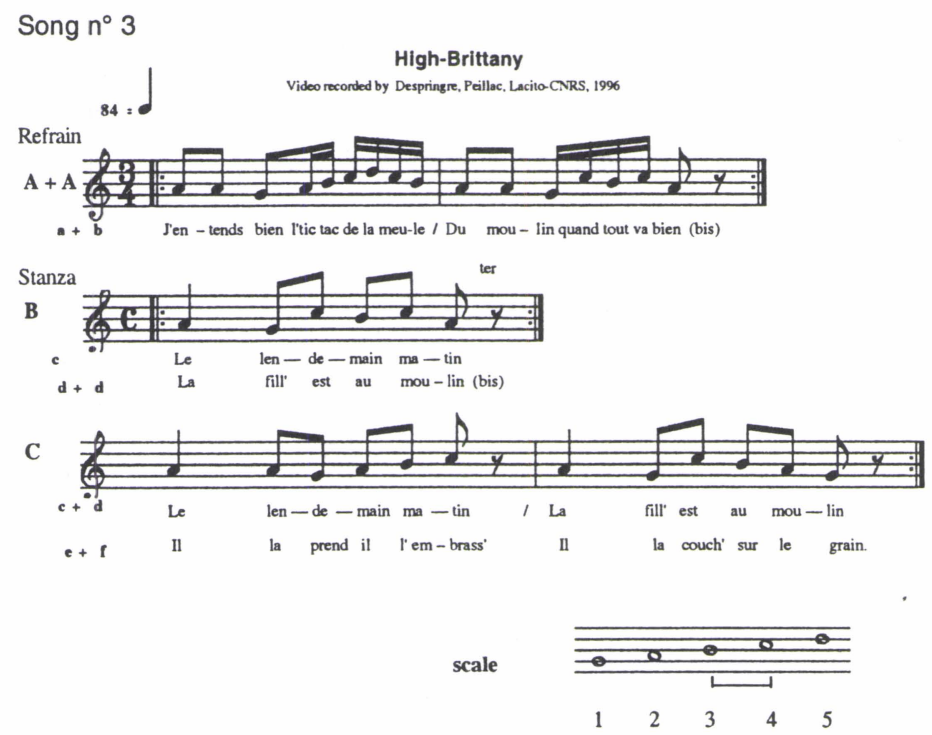

Example 3. Music and text for song no. 3.

\footnotetext{
${ }^{5}$ Video filmed by the author in the wood, near Peillac, during marching song of "9th walk-song", Festival of chestnut, Redon, Brittany, 1996
} 


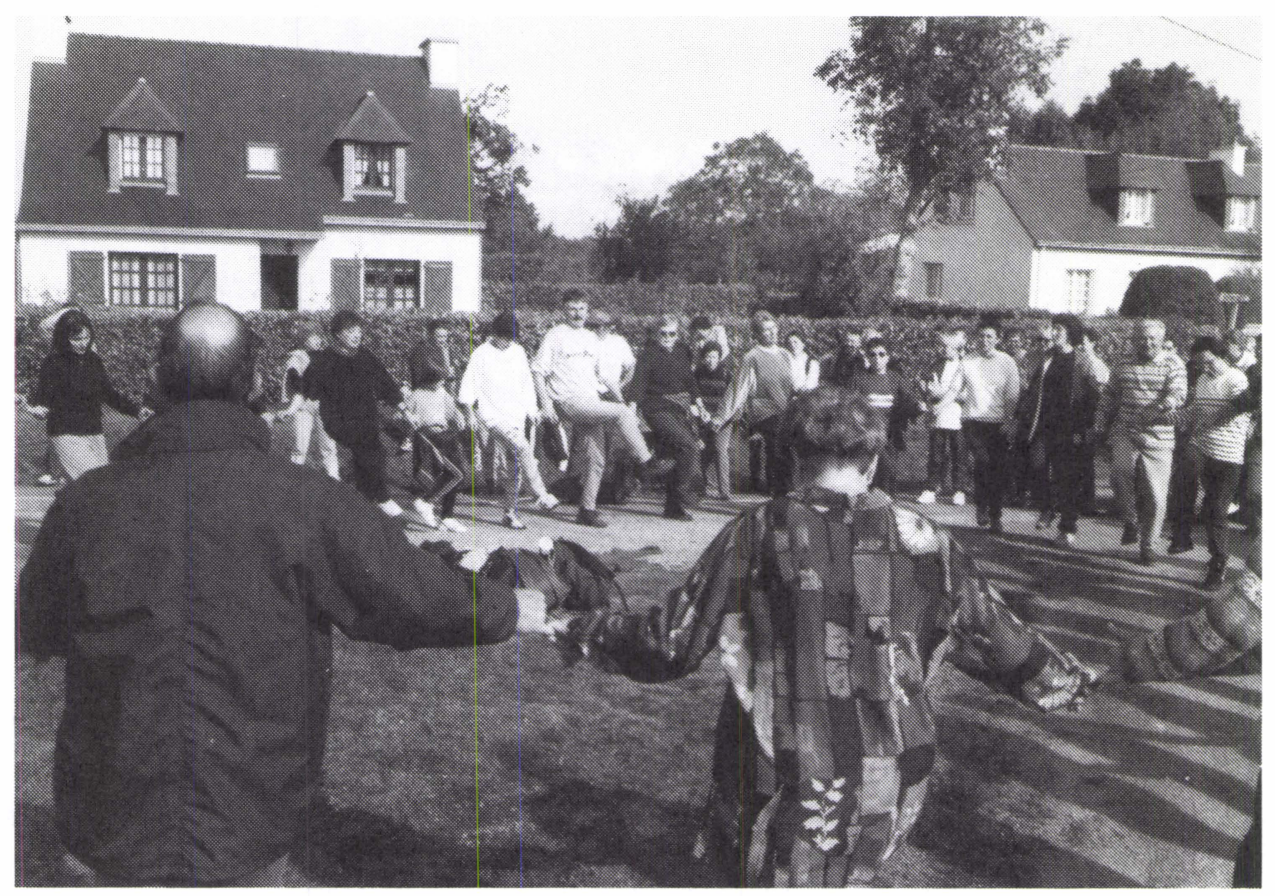

Photo 1. Miller's Song. Hanterdro dance around Peillac Village, Brittany, France. October 1998. A.-M. Despringre.

\section{Expressive systems: poetic and musical comparisons}

Music and text: forms of expression (see Table 2.)

A global analysis (of the versions in Ex.1, 3 and 4) shows a formal organization which seems constrained by the structure of the dance. The first song is performed by a 'branle', the second by a succession of two Breton dances formally very close to each other. The second is performed by the 'hanterdro' (ternary) and the 'endro' (binary). We will note that in the orally transmitted songs, the ternary rhythm always coincides with a structure that has six beats. We see also that this same structure can belong indifferently to a verse or a refrain. Finally the coda of instrumental version 4, alternates the ternary and the binary on a cycle of nine beats repeated ad libitum (here $5 \times 9$ ). Five cycles of a total of 45 beats $(27$ ternary for 18 binary), even though the song only has $12+16$ that is a total of 28 beats and alternates between ternary and binary rhythm in that proportion. The revivalist musicians let their imagination run wild since they are no longer constrained by the metric framework of the dance. That is why they have lengthened the song considerably. 


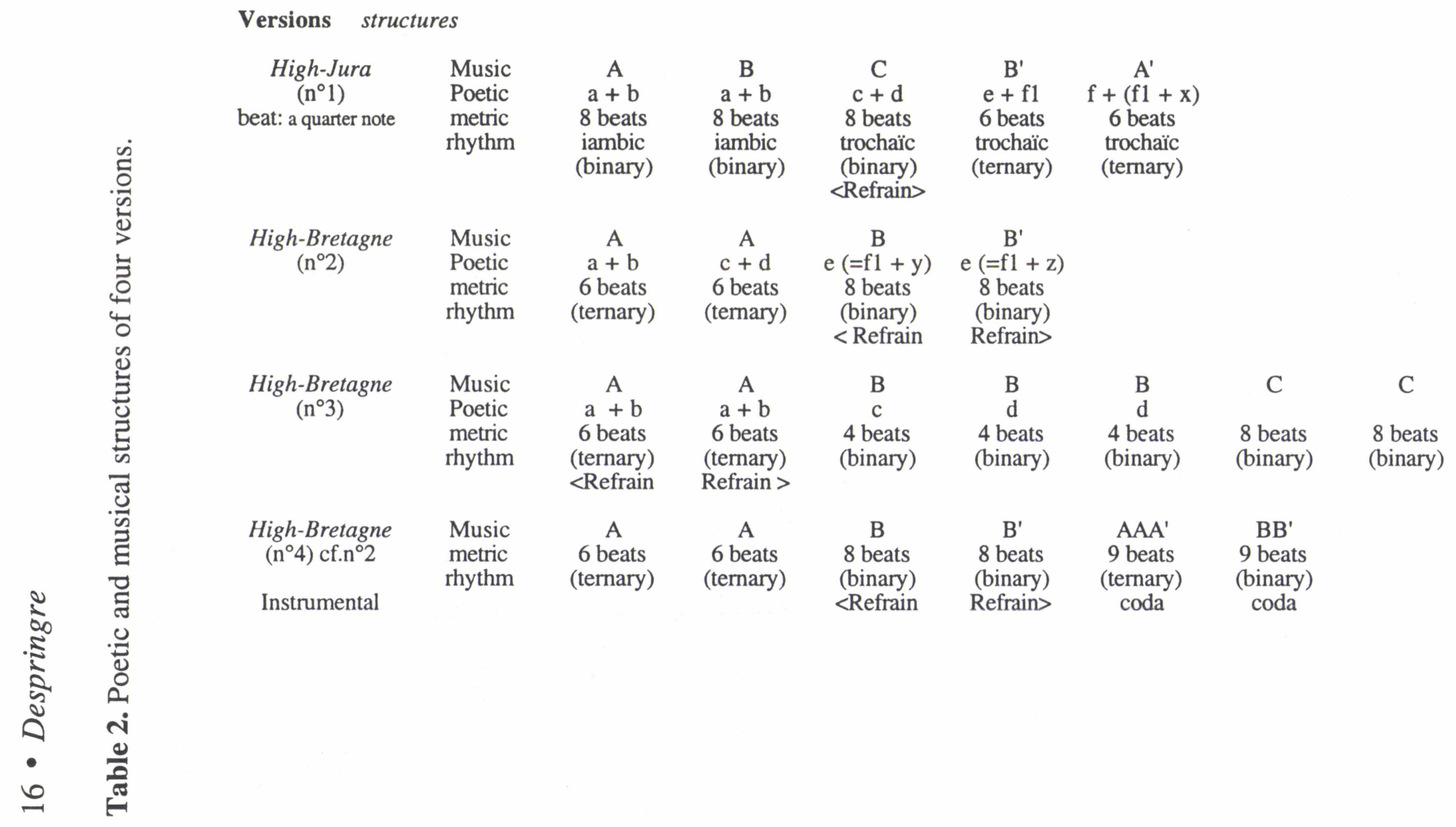


Expressive system of the dance

Dance: form of expression

Dance is in a circle: endro/hanterdro (opposing a binary and a ternary rhythm successively). This danced song is identified by the superimposition of a ternary danced structure on a chanted poetic-musical system which alternates between a ternary and a binary structure.

This creates a temporal shift (two beats) between the poetic-musical structure and the danced one. This shift is compensated by the singer who plays around with the pauses and accentuates the beginning of each refrain. Several less experienced dancers will have some difficulty maintaining the dance rhythm which as a matter of fact does not match the music.

Table 3. Dance system of the basic "Gavotte" in Brittany
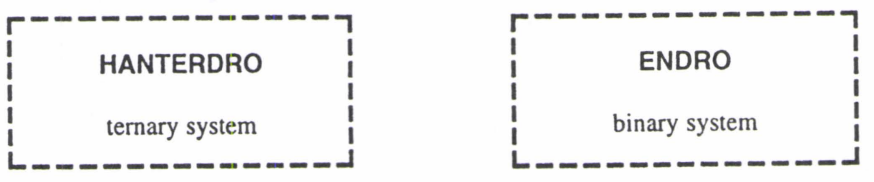

CYCLES

(Beats)

DURATIONS

FEET
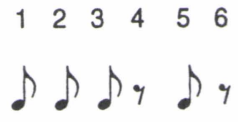

L R L - R - $\begin{array}{llllllll}1 & 2 & 3 & 4 & 5 & 6 & 7 & 8\end{array}$

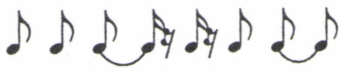

L R L - R L R -

Note :

Feet come from Hanterdro

Arms come from Endro (look at table 4)

Songs have both hanterdro and endro systems $(6+8$ beats, ternary and binary rhythm). 


\section{Music and dance: a fonctif of replication}

Two types of Breton dances are used in this sequence: type 1: Hanterdro, type 2: Endro (see Table 3). Hanterdro - also called the 'knitting' (or 'tricotine' of Pleucardeuc in Morbihan) - consists of scissored arms, and a wound up loop (arms are pointing back towards the shoulders) and a wound out loop (arms are pointing down from the shoulders). Laterality is achieved by the scissored movement of the arms and verticality is achieved by going up and down in loops. The arm movements might symbolize a knitting woman's movements, hence the name of 'tricot'. We could see alternating woman and man, singer and response of the chorus.

With endro (the second type of the dance), binary rhythm, and ternary rhythm are mixed. The rhythmic result of this performance is shown on the Table 3.

\section{Analysis of the sketches}

The double segments and the variant segments occur on different' syntagmatic' axes. The double ones are more frequent in this case. On the paradigmatic level, one finds numerous variances. The main one is the punctuation of the musical discourse. The shadowed areas show the strict connections between the double segments of different levels (poetic, pitches and duration of the sounds, duration of the arms, laterality, and verticality of the dances). Some shifting is noticed between the poetic and musical system, the musical and the danced rhythm. This is especially noticed in this example of the danced song 'Hanterdro/endro' which is danced while borrowing movements from both dances, the 'hanterdro' step, the 'endro' arm movement and a poetic-melodic system that nevertheless conforms itself to the two distinct dances (Table 3). The poetic, musical and kinetic elements, as I have transcribed it, act as iconic symbols. They are represented and recognized by our occidental culture as examples of sounds that we hear, gestures that we see. They are recognized on a base of formal characteristics that I chose as pertinent or on a base of similarity. I think of the variants as being similar but also of the new combinations of rhythmic and melodic elements often identical to parts of some sequences seen earlier.

I have put together the different segments on the basis of the replication principle: whether elements are texts (verses), metric units (verses, rhythm, dance), temporal units (duration of syllables, dance steps), or gestures (laterality of the body by alternating the left and right foot, verticality and laterality of the arm movements by swinging or looping up or down). 


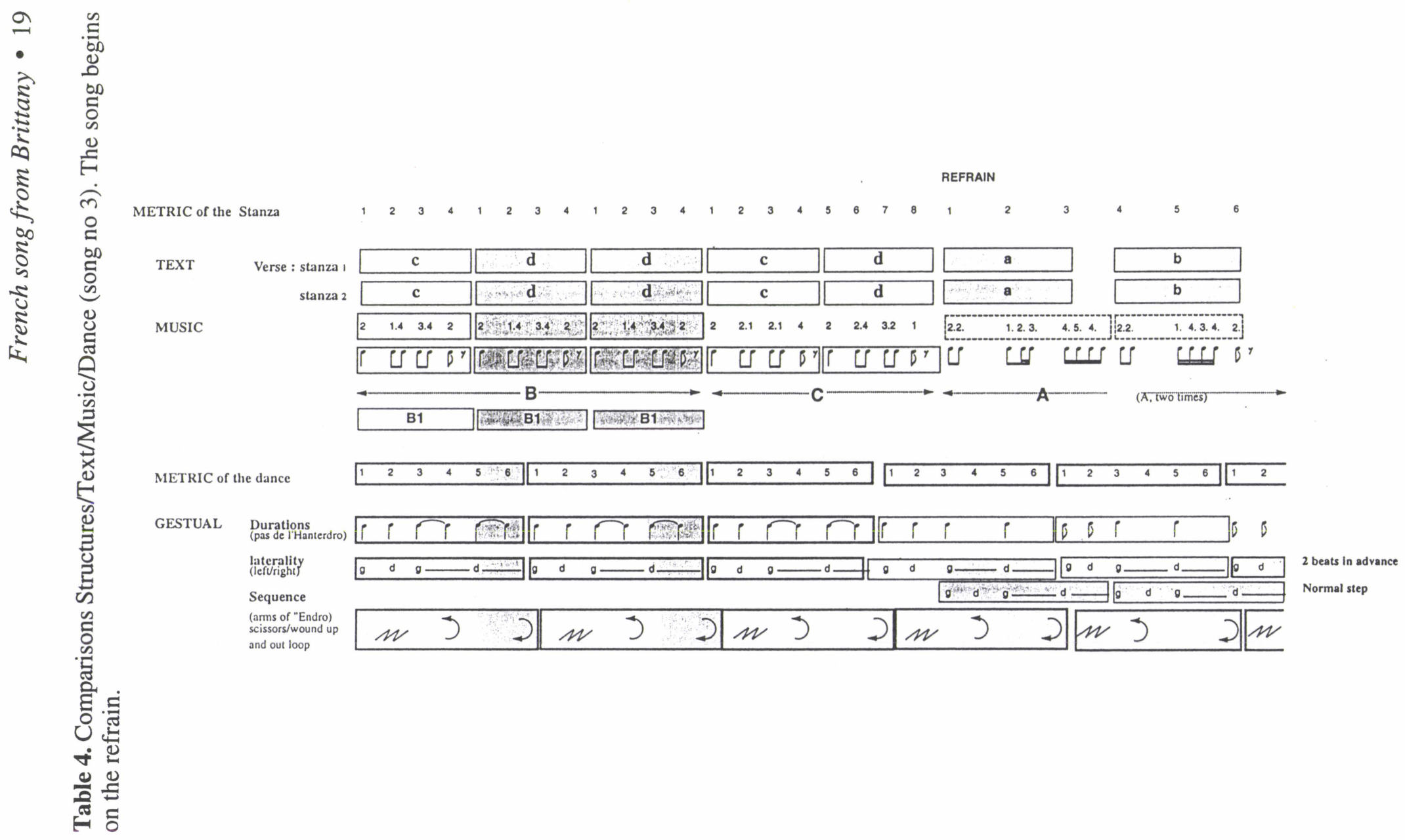




\section{Level III: Passage from the vocal to the instrumental: Another fonctif}

This interpretation of the Miller's Song (Ex. 4) is played by instruments without dancing. This orchestra is playing the same 'air' with diatonic accordion, helped by a violin, then by bagpipes (Breton 'biniou') and an oboe ('bombarde') played by collectors/ singers of High-Brittany and recorded on a compact disc.

\section{Song $n^{\circ} 4$}

INSTRUMENTS (High-Brittany)
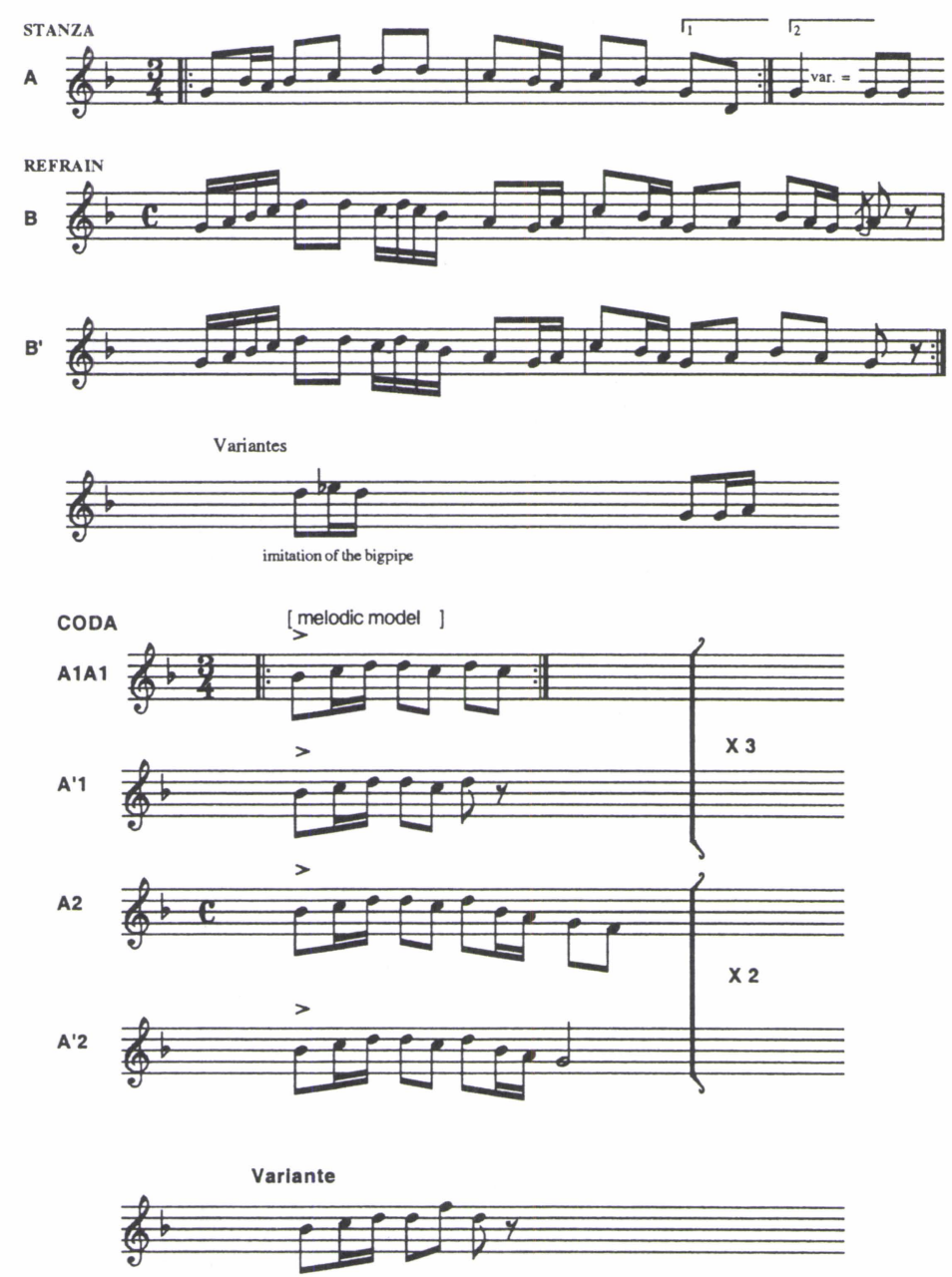

G min. without sensible

Example 4. Music for song no 4. 
It is now an open form with coda which is an added or improvised segment which is not needed by the initial system (very close to Ex. 2). Deletion of a structure does not affect the dance-system. The danced steps represent a ternary structure.

The characteristics of the new form stand mainly in the coda which add: repeated groups, repeated segments; new construction on a melodic model.

\section{Expression of the rhythm:}

The first structures (in phrases A, B, B') are preserved. The second part or coda is simplified by 'repeating' the rhythmic group of stanza A.

\section{Content of the melody}

In stanza A, the 'ambitus' is enlarged to reach the lower 'A' (la) (D F G A B C D instead of G A B C D). Some variations are introduced by the bagpipe (biniou) which I have written on the transcription. Then, in the coda, the melodic structure which I have extracted in the Table 1 is almost solely reproduced here according to the same replicating system (underlying segments below:

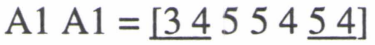

$$
\begin{aligned}
& \mathrm{A}^{\prime} 1=[\underline{3} 45554 \text { 占] }
\end{aligned}
$$

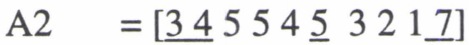

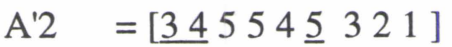

\section{Form of expression}

The cycles of this coda are alternatively ternary ( 24 beats) and binary (16 beats) instead of $\mathrm{A}+\mathrm{A}=12$ beats (ternary) and $\mathrm{B}+\mathrm{B}^{\prime}=16$ beats (i. e. first part before the coda). Without the coda, all the normal song (Ex. 2) is given two times, successively, which means a total of 56 beats, longer than the normal way of the dance which is 40 beats. That means also that it could be impossible to preserve the alternative ternary/binary which must be done to dance.

\section{Form of content}

The tripartite ' $\mathrm{A}$ ' structure, frequently used as a model in Brittany has been introduced in the coda. A1 = a melodic part of A, combined in a different way on a melodic structure and a rhythm coming from the ' $\mathrm{A}$ ' of the song No. 2: another combination of the same principle $\mathrm{A}^{\prime} 2$ is a variation of $\mathrm{A} 2$

The instrumental 'coda' does not respect the rhythmic framework of the dance 'hanterdro/endro' and we have seen that it is a simplified version of the A of the song. 


\section{Are stylistic and formal modifications consequences of this situation? Applying the replication principle}

The analysis methodology aims to show the incidence of the instrument on the variation and musical mutations, be they formal or stylistic. The respect that the music of Brittany pays to musical foundations manifests itself in different ways depending on the degrees of conscious hold of the stylistic or formal authenticity. This explains the important diversity of interpretations of the same monodies that we notice in Brittany.

The paradigmatic and distribution methods that I use, rely on the replication criteria of the different musical elements considered (Eco 1973; Crochu et al 1991; Despringre 1992). They am at identifying those that seem most pertinent to represent the poetic and musical systems of a region and to determine its collective styles. The variety of structures and systems is put in evidence in this way on the basis of the noted musical foundations. Expressive systems and contents that are tied to the use of forms are described for the song as well as for its instrumental interpretation. Significant differences appear, in the organization of forms or contents, as well as in the utilization of the specific possibilities of each instrument considered ('biniou' / 'bombarde', accordion, violin, clarinet of Brittany), or in the conditions of performance. Putting these differences in perspective using the Miller's Song as an example of an 'iconic dominant model', has given following results.

I have proceeded with three kinds of comparisons: first, comparing a song between two cultures (High-Jura and High-Brittany), then, within the same culture, and one song with the dance and passage from a song to an orchestra.

So, the iconic representations of the sounds that I have transcribed as they are organized in a monody, sends us back not to what we hear of the song but to what I know of the music and also what I have learned to hear and write. The scores are not a reflection of reality but a result of conventions that fix duration, intensities, cycles in function of the replication criterion. The scores that I have shown are 'modelled texts which might serve to understand a process of musical evolution.

I have explained some parts of the dialectic between songs, music, and dance (which is an immediate context or a co-rhythm), and the taking out of context. First, the song and the prevalent ideology restores the instruments and rebuilds a sound universe which is close to other recognized Celtic cultures. Secondly, the song and musical instrument give partial autonomy of the opening form. A change has taken place from one closed and constricted form to another more open and expansive. Musical tones of a music that has preserved its essential characteristics, illustrate a modernization more than any changes or musical contents. The songs and music performers are often one and the same. This is why the changes are displayed more in the styles than in the musical basis.

Then, several levels of replication of a song and its context could be distinguished: 
First level (external to the song): Re-utilization of an ancient melody as an iconic identity model.

Second level (internal): The rhythmic expression (establishing the units: syllables, duration, intensity on a basis of alternating and contrasting parameters), height of the sounds, phonetic expression of the French language.

Third level (internal): The melodic expression (scales, rhythmic systems)

Fourth level: (internal): The forms of the poetic contents (the meaning of rhetoric images: metaphors), the forms of the rhythmic-melodic contents (rhythmic and melodic units, measure of the schema of accents, intervals series or motifs etc.).

Fifth level (internal): Replication of the noted segments, system by system and between systems.

Sixth level (internal / external): relationships between the transformations of the expressive forms and of the ideological context: Replication of the instrumental models, explanation of the existence of particular tone groupings (imitations of the playing of the Celtic violin, development of a coda that is independent of the text but not of the dance).

\section{Conclusion}

Four major operations structure the approach of the degrees of replication in music:

1 . The study of the process of re-appropriation of sung tales - by imitation and the role of the collecting associations in the filtering of behaviours. Elaboration strategies for the new musical 'instrumented' styles also appear. These strategies are motivated more by the cultural identity and the musical instruments than by the musical content.

2. The comparative study of the oral statute (relationship between oral and written...). The orality of the written word, the written part of the oral word to represent poetic-musical structures, either in the concrete aspect of a performance or on a score.

3. The description of varying perceptions - vocal and instrumental - after a non-variant (see Ex. 4).

4. The ultimate distinction of the same and different by comparing versions of the same song in varying circumstances.

Both, music and dance maintain and transmit - by emphases - cultural identity of Bretons. But, little by little, texts are forgotten. That is a sign of a changing situation which modifies contents and even the forms of music by using more and more instrumental orchestras. 


\section{References}

Alvarez-Pereyre, Frank \& Arom, Simha 1991. Ethnomusicologie. In Dictionnaire de l'ethnologie et de l'anthropologie. Ed. P. Bonte et M. Izard. Paris: PUF: 248-251.

Arleo, Andy \& Despringre, André-Marie 1997. Musilinguistique du chant enfantin. Chants enfantins d'Europe. Ed. A.-M. Despringre. Paris: L'Harmattan: 15-30.

Arom, Simha 1982. Nouvelles perspectives dans la description des musiques de tradition orale. Revue de musicologie. Paris: 198-212.

Crochu, Dominique and al. 1991. Despringre, André-Marie (Dir). Poésies chantées de tradition orale en Flandre et en Bretagne. Paris: Champion [Musilingue].

Despringre, André-Marie 1992. Puzzle musical. in P. Laburthe (ed. ): Conter et chanter en pays de Redon. Paris: L'Harmattan: 71-89.

Despringre, André-Marie 1994. Professionalisation of traditional musicians from the French regions and instrumental reconstruction of vocal music. Selected articles of the XI European Seminar in Ethnomusicology. September 1994. Oxford. ESEM. webmasters@music.ed.ac.uk.

Despringre, André-Marie 1997a. Catégoriser un rythme 'flamand'. Anthropologie et Cognition. Journal des Anthropologues. 70: 73-90. Paris [AFA].

Despringre, André-Marie 1997b. Mémoire et Survie de la musique bretonne in: Etudes sur le folklore et les traditions populaires. Bastidiana. Caen. No. 1920:193-208.

Despringre, André-Marie 1997c. Tradition orale desformes poético-musicales de France: quelques problèmes d'interprétation. In De la voix au texte. Ed. Nicole Belmont et Jean-François Gossiaux. Toulouse: CTHS: 71-85.

Despringre, André-Marie 1997d. Le chant du meunier: danse endro/hanterdro. vidéo $8 \mathrm{~mm}$, pré-montage. LACITO-CNRS $5 \mathrm{~min}$. Paris.

Eco, Umberto 1992 [1973]. Le signe. Paris: Editions Labor [Biblio essais, livre de poche].

Eco, Umberto 1992 [1976]. La production des signes. Paris: Editions Labor [Biblio essais, livre de poche].

Frances, Robert 1958. La perception de la musique. Paris: Vrin.

Hjelmslev, Louis 1971 (1943). Prolégomènes à une théorie du langage. Paris: Minuit.

Imberty, Michel 1975. Perspectives nouvelles de la sémantique musicale expérimentale. Musique en jeu. No. 17: 87-109.

Imberty, Michel 1993. Développement linguistique et musical de l'enfant d'âge pré-scolaire et scolaire. E. S. C. O. M. No. 3: 19-23.

Molino, Jean 1975. Fait musical et sémiologie de la musique. Musique en Jeu 
No. 7: 37-62. Paris.

Nattiez, Jean-Jacques 1976. Fondements d'une sémiologie de la musique. Paris: Union générale d'édition 10-18.

Nattiez, Jean-Jacques 1987. Musicologie générale et sémiologie. Vol. I. Paris: Bourgois.

Peirce, Charles Sanders 1931/35. Collected Papers. Harvard. Cambridge: Mass: Harvard University Press.

Ruwet, Nicolas 1975. Théories et méthodes dans les études musicales: quelques remarques rétrospectives et préliminaires. Musique en jeu. No. 17: 11-35 Paris. 
Appendix 1. Texts of the three songs.

\author{
Text 1 (High-Jura) \\ Incomplete text \\ 1.The milling miller \\ Is a good-looking blond \\ $\underline{\text { Refrain }}$ \\ Come running quickly \\ Young lady to grind \\ Run to see the miller \\ For he is going to mill
}

2.(similar to \# 9 of Text 1 )

What will my mother say

To see my bag so full (bis)

3)You will tell her, pretty lady

That it is the tic-tac of the mill (similar to the second verse of \#11 of Text1)

\section{Vidéo}

Text 2 High-Brittany

(Hanterdro/endro)

Text 3 (High-Brittany)

"Hanterdro/endro"

\section{Incomplete text}

1.Behind my father's house There is a miller's house The miller who lives there It is a happy blond chap

Refrain

I can hear the tic-tac of the millstone Of the mill when all's well (bis) (Ref. 2-5)

Refrain

Come back pretty lady For my mill is going Come back pretty lady For he is going to mill.

2. An old lady passed by Who wanted her grain milled

3. For you old lady

My mill is not milling

4. If you have a daughter Bring her here to-morrow

5. When the young lady arrives The mill was running well

6. The young lady fell asleep By the tic-tac of the mill

7. And when she wakes Her little bag was full

8. Full of white flour the whitest ever

9. What will my father say To see my bag so full?

10. You will tell them, pretty lady (1-3)

that it is Miller Mathurin

11. Who caresses pretty girls by the tic-tac of the mill
The next morning

The girl is to the mill

He held her, he kissed her

He laid her on the grain 